
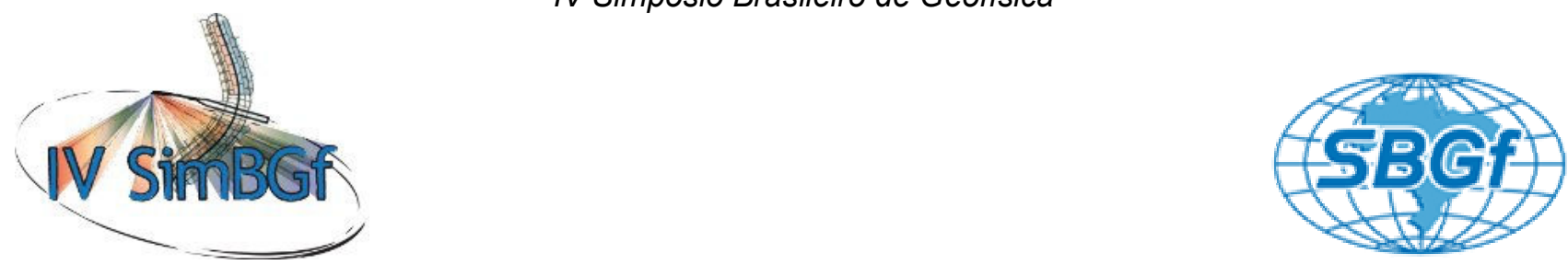

\title{
Aplicação do método eletromagnético VLF na prospecção de água subterrânea no município de Piçarra - PA
}

Gilvana Bezerra de Sousa*, CPGF / UFPA, Brasil

José Gouvêa Luiz, CPGF \& Faculdade de Geofísica / UFPA ,Brasil

Copyright 2010, SBGf - Sociedade Brasileira de Geofísica

Este texto foi preparado para a apresentação no IV Simpósio Brasileiro de Geofísica, Belém, 14 a 17 de novembro de 2010. Seu conteúdo foi revisado pelo Comitê Técnico do IV SimBGf, mas não necessariamente representa a opinião da SBGf ou de seus associados. É proibida a reprodução total ou parcial deste material para propósitos comerciais sem prévia autorização da SBGf.

\section{Abstract}

Prospection of groundwater in basement rocks environment using the EM-VLF method was performed in Piçarra city, southern of Pará. The results showed conductors associated to fractures in the basement rocks, allowing the indication of several sites for drilling wells as promising to get water for the municipality supply.

\section{Introdução}

Do ponto de vista geológico, pode-se classificar os ambientes de ocorrência da água subterrânea em dois grandes tipos: o ambiente sedimentar e o ambiente de embasamento. O sedimentar é caracterizado por uma grande espessura de rochas sedimentares (acima de 50 $\mathrm{m})$ recobrindo as rochas do embasamento cristalino. No ambiente de embasamento a cobertura sedimentar é pouco espessa e geralmente argilosa, pois provém do intemperismo das rochas do embasamento. Como as rochas cristalinas apresentam baixa porosidade primária (que mede a quantidade de água que a rocha pode conter) e baixa permeabilidade (que mensura a capacidade da rocha ceder sua água), torna-se difícil conseguir água subterrânea em quantidade suficiente para o abastecimento. Quantidade suficiente de água nesse ambiente somente pode ser encontrada em fraturas que cortam as rochas do embasamento cristalino. A figura 1 ilustra o ambiente de ocorrência de água subterrânea em áreas de embasamento.

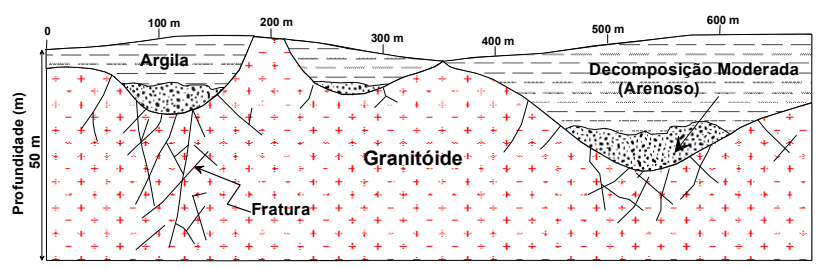

Figura 1 - Ambiente de embasamento próximo da superfície do terreno mostrando fraturas preenchidas com água (adaptado de van Lissa et al., 1987).
Este estudo teve como objetivo o mapeamento de lineamentos associados a fraturas do embasamento através de geofísica, usando o método eletromagnético VLF no Município de Piçarra, localizado no sul do estado do Pará. O estudo forneceu indicações dos melhores locais para a construção de poços de captação de água para o abastecimento da cidade.

\section{Geologia}

$\mathrm{Na}$ sede do município de Piçarra, predominam rochas metamórficas classificadas como micaxistos pertencentes à Formação Pequiseiro, que apresentam uma foliação com azimute de $350^{\circ}$ e mergulhos entre $15^{\circ}$ e $25^{\circ}$ (Corrêa, 1998).

De acordo com Corrêa (1998), os micaxistos da Formação Pequiseiro apresentam um manto de alteração com espessura variando de 1,5 a $12 \mathrm{~m}$, constituído por uma fina camada laterítica com cerca de $15 \mathrm{~cm}$, seguida de horizonte argiloso com 10 a $20 \mathrm{~cm}$ de espessura nas partes centrais da cidade, podendo chegar a $50 \mathrm{~cm}$ de espessura nos altos topográficos. Após o horizonte argiloso ocorre um saprólito constituído, principalmente, por fragmentos de rochas parcialmente alterados envoltos em matriz argilosa. As rochas menos alteradas apresentam um micro-fraturamento com densidade tal que, a cada $2 \mathrm{~cm}$, há cerca de 5 fraturas espaçadas de $0,5 \mathrm{~cm}$.

A água usada no abastecimento doméstico da cidade provém de poços do tipo Amazonas, cavados até profundidades que variam de 6 a $14 \mathrm{~m}$ pelos próprios moradores nos seus quintais. É comum esses poços estarem localizados às proximidades de latrinas (buracos com cerca de $2 \mathrm{~m}$ de profundidade). As rochas metamórficas (do tipo que ocorre em Piçarra) são normalmente incapazes de produzir água subterrânea em quantidade suficiente para abastecimento, devido a sua baixa porosidade e baixa permeabilidade. Somente em condições especiais, como por exemplo, quando essas rochas contêm fraturas, é possível conseguir-se extrair água suficiente para o abastecimento.

$\mathrm{Na}$ área da cidade de Piçarra há duas possibilidades para obtenção de água: a primeira consiste na retirada da água do material arenoso identificado nos poços Amazonas e no poço tubular da Lavanderia Pública; a segunda possibilidade é a retirada da água contida nas fraturas dos micaxistos. No caso da primeira possibilidade é necessário que se tenha uma grande 
espessura de material arenoso para que se obtenha uma grande quantidade de água; ainda, nesse caso, é recomendado que o material arenoso, de onde será retirada a água, esteja isolado da superfície do terreno por uma camada impermeável de argila, a fim de que não haja contaminação da água por materiais e agentes nocivos à saúde.

\section{Metodologia}

A água subterrânea no tipo de ambiente geológico que ocorre em Piçarra provavelmente localiza-se em fraturas. O método eletromagnético constitui uma boa alternativa para detectar tais estruturas nas áreas de embasamento da região.

Neste trabalho as medidas eletromagnéticas foram realizadas com o método VLF. As medidas foram realizadas a intervalos de 10 metros, ao longo de nove ruas (Minas gerais, Paulo Fonteles, Tancredo Neves, Raimundo Gringo, Carajás, Dois Irmãos, Raimundo Mota, Maria José de Jesus e Cândido Alves) da sede do município de Piçarra, totalizando 340 metros de medidas (Figura 2).

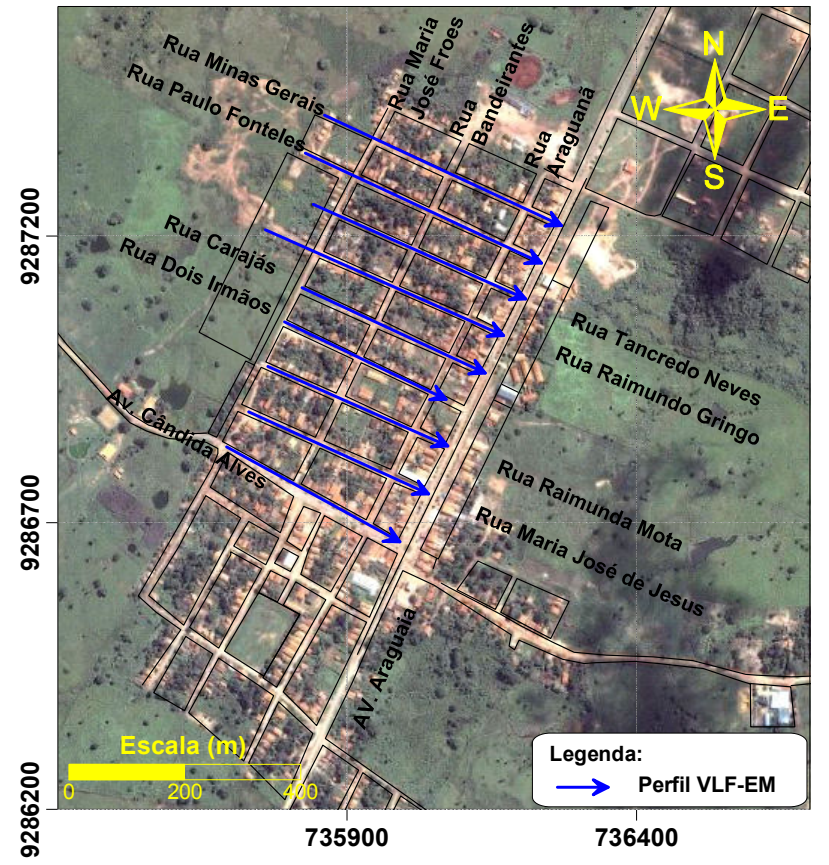

Figura 2 - Mapa de localização do Levantamento Geofísico.

Durante o levantamento foram medidos o azimute e a inclinação do campo magnético resultante na freqüência de $18,5 \mathrm{kHz}$; porém, somente a inclinação do campo foi analisada e interpretada. $\mathrm{O}$ instrumento utilizado para as medidas foi o receptor VLF SCOPAS da Universidade Federal do Pará, modelo SE 81, fabricado pela companhia Scintrex.

Fraser (1969) desenvolveu um filtro numérico simples, que transforma o crossover da anomalia VLF (que indica a posição do condutor associado à fratura), em um pico positivo (Figura 3). Esse processo de filtragem deixa os dados apropriados à confecção de mapas de contorno, que permitem melhor visualização das estruturas geológicas que produzem os sinais anômalos. Fraser elaborou este filtro, para satisfazer os seguintes critérios:

1- deslocar de 90 graus os dados de inclinação, para converter o crossover em pico positivo;

2- atenuar o grande comprimento de onda, para aumentar a resolução da anomalia local;

3- não aumentar os ruídos randômicos nos dados; e

4- ser de fácil aplicação.

Os dados coletados no levantamento com VLF em Piçarra foram processados com o Filtro Fraser e, posteriormente, representados na forma de perfis e mapa de contornos.

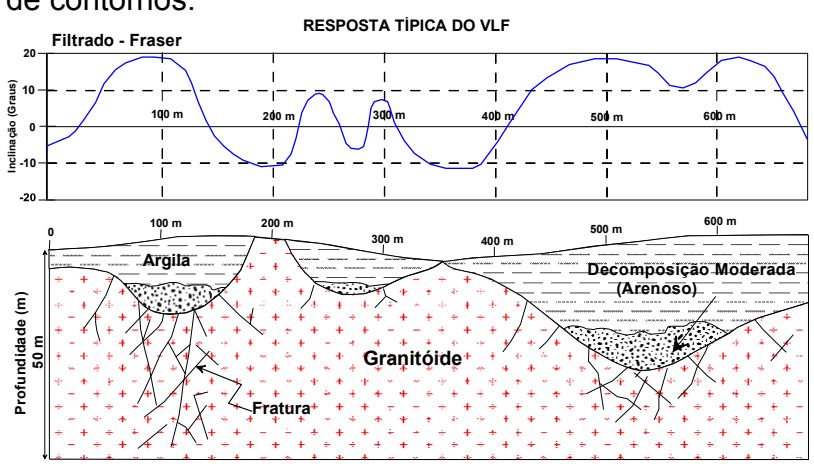

Figura 3 - Resposta típica dos dados VLF (após processados com o Filtro Fraser) sobre o ambiente de ocorrência de água subterrânea em fraturas (adaptado de van Lissa et al., 1987).

\section{Resultados}

Os valores dos ângulos de inclinação do campo magnético resultante estão representados na forma de perfis nas Figuras 4 e 5 . Para comparação, foram também representados nessas figuras os valores filtrados. Observa-se nas figuras que os crossovers dos valores de ângulos de inclinação (indicativos da projeção do eixo dos condutores na superfície) correlacionam com picos positivos dos valores filtrados, como recomenda Fraser (1969). Isso demonstra que o filtro foi aplicado corretamente e que a análise dos dados pode ser feita a partir dos dados filtrados.

Na Figura 6 estão representados os valores filtrados na forma de contornos de isovalores. Aparecem na figura apenas contornos dos valores positivos a fim de torná-la mais simples de visualizar, permitindo que se identifiquem os eixos dos condutores mais facilmente.

As projeções dos eixos dos condutores na superfície, conforme sugestão dos contornos dos valores filtrados, estão representadas na Figura 7. Observam-se na figura diversos eixos de condutores com direção preferencial NS, que estão provavelmente associados a fraturas do embasamento. 


\section{Conclusões}

A aplicação do método eletromagnético VLF na sede do município de Piçarra evidenciou diversos eixos de condutores com direção preferencial NS. Esses condutores devem estar associados a zonas de fraturas localizadas nas rochas do embasamento e são os locais mais indicados para a locação de poços de captação de água para o abastecimento da cidade.

Com o uso do filtro Fraser, a identificação dos eixos dos condutores pode ser feita de modo mais fácil e eficaz.

\section{Agradecimentos}

A autora Gilvana Bezerra de Sousa agradece ao programa de Pós-Graduação em Geofísica da UFPA pela oportunidade de realizar a pesquisa.

Aos técnicos Afonso Quaresma de Lima e Álvaro Prestes pelo auxilio na coleta dos dados geofísicos.

Ao amigo Allex Raiol pela ajuda na elaboração dos mapas deste trabalho.

\section{Referências}

Corrêa, J.A.M. 1998. Projeto de avaliação da água em aqüíferos livres na cidade de Piçarra no município homônimo. Relatório preliminar. Centro de Geociências da Universidade Federal do Pará, 7p.

Fraser, D.C. 1969. Contouring of VLF - EM data. Geophysics, v. 34, p. 958-967.

Van Lissa, R.V.; Van Maanen, H.R.J.; Odera, F.W. 1987. The use of remote sensing and geophysics for groundwater exploration in Nyanza province - Kenia. African Water Technology Conference, Nairobi, February 1987.
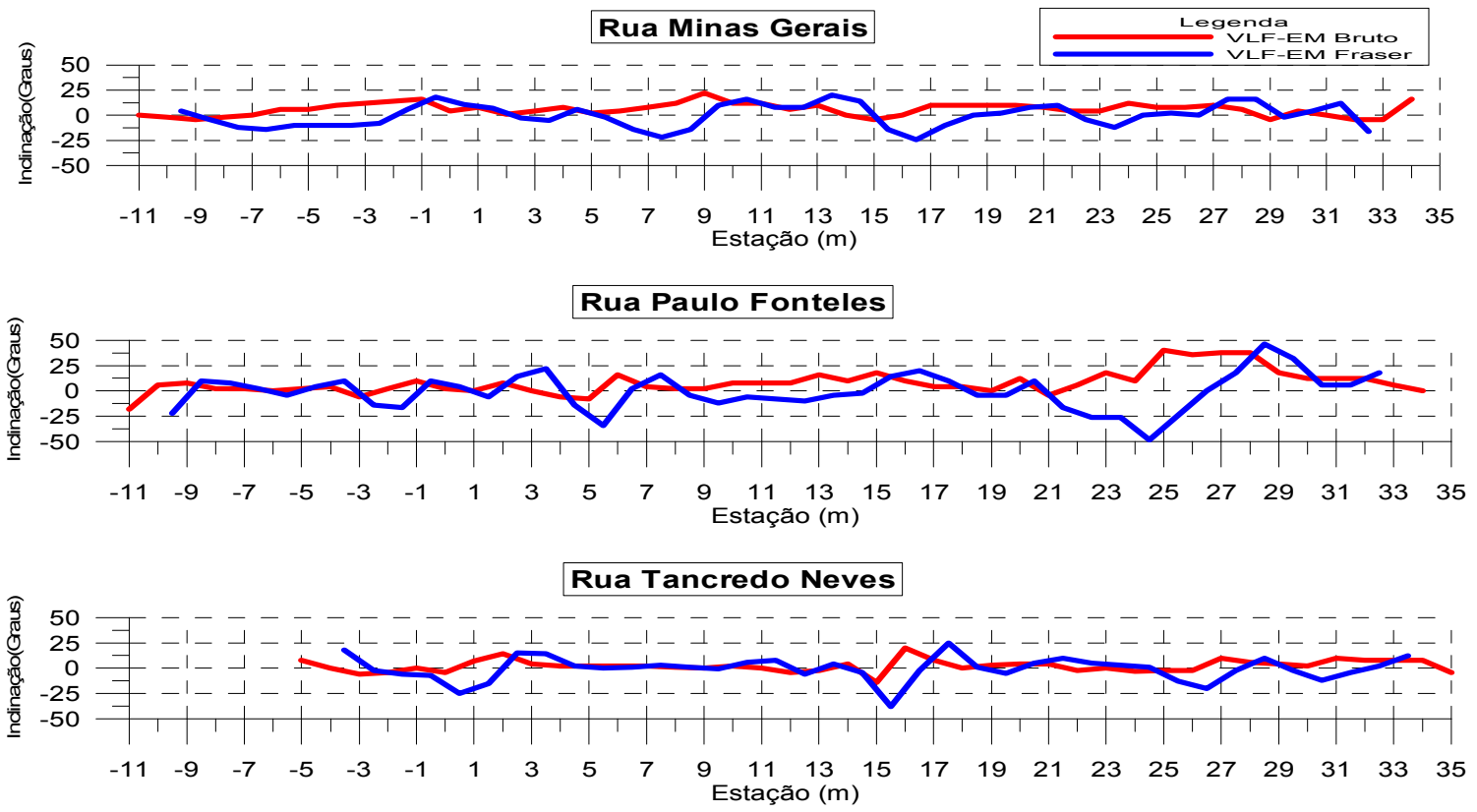

Figura 4 - Perfis VLF dos valores de ângulo de inclinação do campo magnético resultante (linha vermelha) e valores filtrados com filtro Fraser (linha azul), para as ruas Minas Gerais, Paulo Fonteles e Tancredo Neves. 

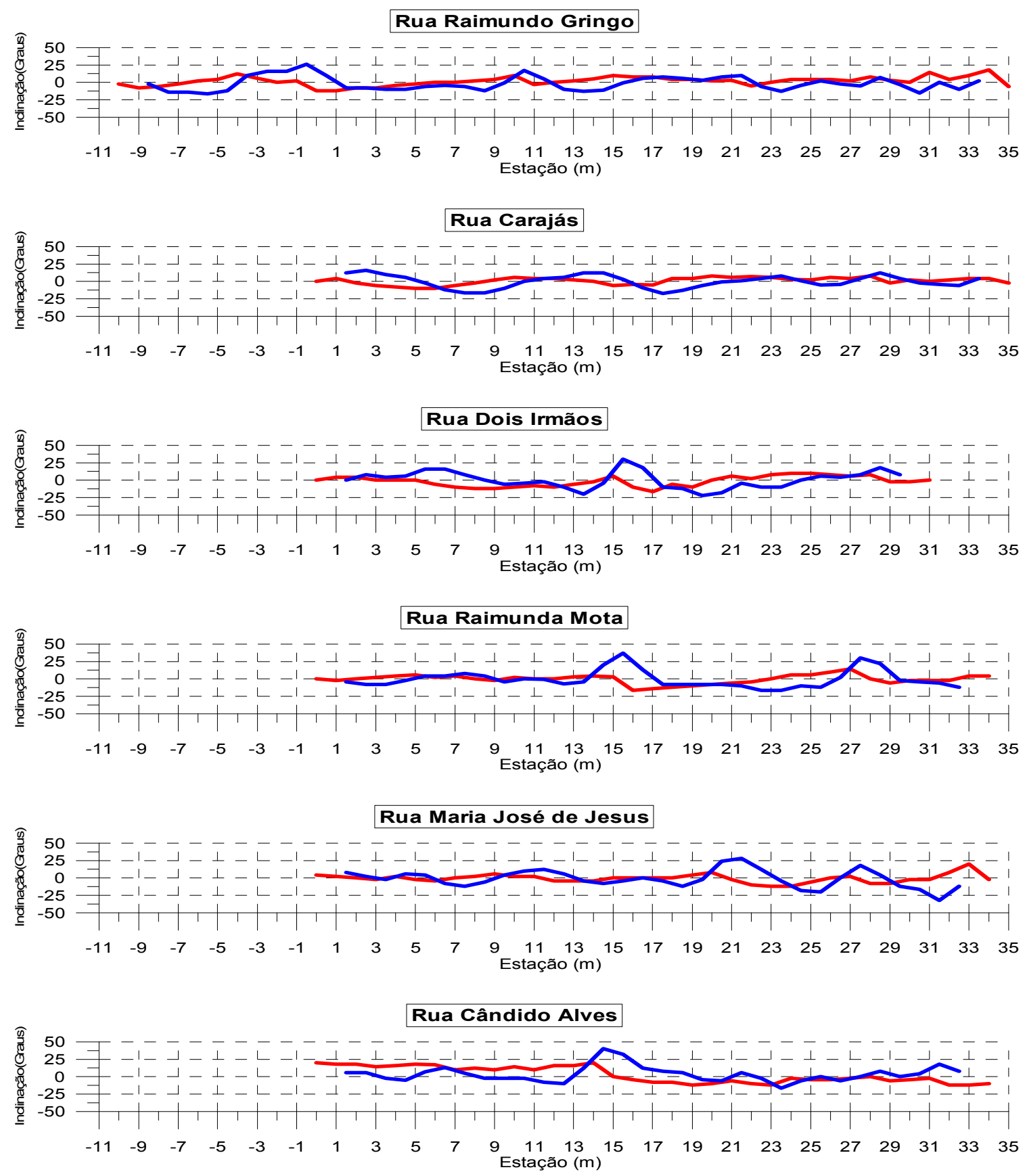

Figura 5 - Perfis VLF dos valores de ângulo de inclinação do campo magnético resultante (linha vermelha) e valores filtrados com filtro Fraser (linha azul), para as ruas Raimundo Gringo, Carajás, Dois Irmãos Raimunda Mota, Maria José de Jesus e Cândido Alves. 
EM-VLF (dados filtrados)

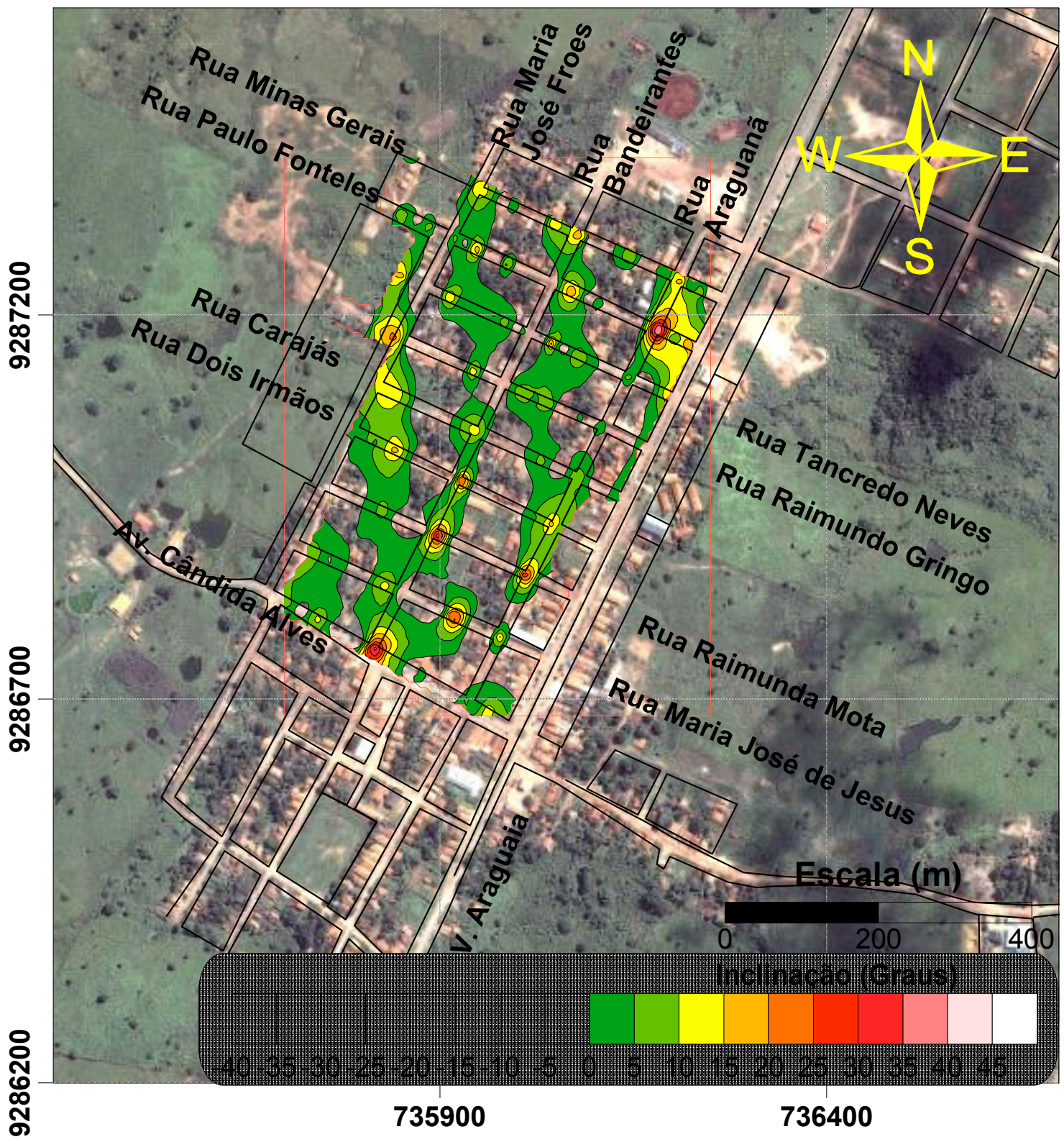

Figura 6 - Mapa de contornos dos valores positivos dos dados VLF filtrados com Filtro Fraser. 


\section{EM-VLF (dados filtrados)}

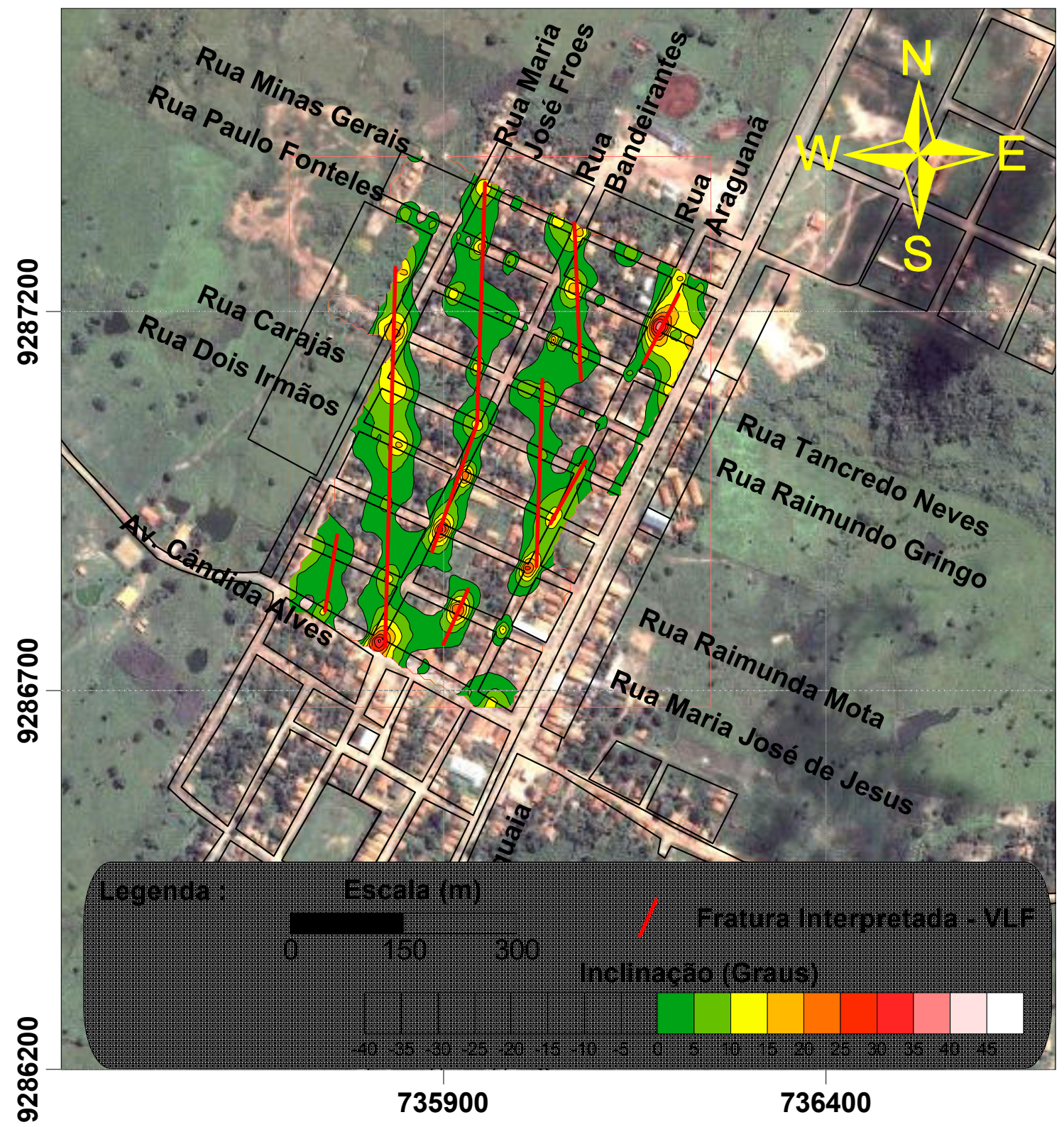

Figura 7 - Representação da projeção dos eixos dos condutores na superfície (linhas vermelhas), sobre o mapa de contornos dos valores positivos dos dados VLF filtrados com Filtro Fraser. Os eixos dos condutores foram interpretados como fraturas no embasamento cristalino. 